\title{
Carbapenemase-producing Enterobacteriaceae circulating in the Reunion Island, a French territory in the Southwest Indian Ocean
}

Guillaume Miltgen ${ }^{1,2^{*}}$, Pascal Cholley ${ }^{3,4}$, Daniel Martak ${ }^{3,4}$, Michelle Thouverez ${ }^{3}$, Paul Seraphin ${ }^{1}$, Alexandre Leclaire ${ }^{1}$ Nicolas Traversier ${ }^{1}$, Bénédicte Roquebert ${ }^{1,2}$, Marie-Christine Jaffar-Bandjee ${ }^{1,2}$, Nathalie Lugagne $^{5}$,

Céline Ben Cimon ${ }^{6}$, Mahery Ramiandrisoa ${ }^{7}$, Sandrine Picot ${ }^{8}$, Anne Lignereux ${ }^{9}$, Geoffrey Masson $^{10}$, Jérôme Allyn ${ }^{11}$, Nicolas Allou ${ }^{11}$, Patrick Mavingui ${ }^{2}$, Olivier Belmonte ${ }^{1}$, Xavier Bertrand ${ }^{3,4}$ and Didier Hocquet ${ }^{3,4}$

\begin{abstract}
Background: The spread of carbapenemase-producing Enterobacteriaceae (CPE) in the Southwest Indian Ocean area (SIOA) is poorly documented. Reunion Island is a French overseas territory located close to Madagascar and connected with Southern Africa, Indian sub-continent and Europe, with several weekly flights. Here we report the results of the CPE surveillance program in Reunion Island over a six-year period.
\end{abstract}

Methods: All CPE were collected between January 2011 and December 2016. Demographics and clinical data of the carrier patients were collected. We determined their susceptibility to antimicrobials, identified the carbapenemases and ESBL by PCR and sequencing, and explored their genetic relationship using pulsed-field gel electrophoresis and multi-locus sequence typing.

Results: A total of 61 CPEs isolated from 53 patients were retrieved in 6 public or private laboratories of the island. We found that $69.8 \%$ of CPE patients were linked to a foreign country of SIOA and that almost half of CPE cases $(47.2 \%)$ reached the island through a medical evacuation. The annual number of CPE cases strongly increased over the studied period (one case in 2011 vs. 21 cases in 2016). A proportion of 17.5\% of CPE isolates were nonsusceptible to colistin. bla NDM $_{\text {Mas }}$ the most frequent carbapenemase $(79.4 \%)$, followed by bla $a_{\text {MI }}(11.1 \%)$, and bla $a_{1 \mathrm{MP}-10}(4.8 \%)$. Autochtonous CPE cases (30.2\%) harboured CPE isolates belonging to a polyclonal population.

Conclusions: Because the hospital of Reunion Island is the only reference healthcare setting of the SIOA, we can reasonably estimate that its CPE epidemiology reflects that of this area. Mauritius was the main provider of foreign CPE cases (35.5\%). We also showed that autochthonous isolates of CPEs are mostly polyclonal, thus unrelated to cross-transmission. This demonstrates the local spread of carbapenemase-encoding genes (i.e. bla $a_{\mathrm{NDM}}$ ) in a polyclonal bacterial population and raises fears that Reunion Island could contribute to the influx of NDMcarbapenemase producers into the French mainland territory.

Keywords: Epidemiology, Carbapenemase, French overseas territory, Reunion Island, Indian Ocean, NDM

\footnotetext{
* Correspondence: guillaume.miltgen@chu-reunion.fr

'Laboratoire de Bactériologie, CHU Félix Guyon, Allée des Topazes, 97400

Saint-Denis, La Réunion, France

${ }^{2}$ UMR Processus Infectieux en Milieu Insulaire Tropical, CNRS 9192, INSERM

U1187, IRD 249, Université de La Réunion, Sainte-Clotilde, La Réunion, France

Full list of author information is available at the end of the article
}

(c) The Author(s). 2020 Open Access This article is distributed under the terms of the Creative Commons Attribution 4.0 International License (http://creativecommons.org/licenses/by/4.0/), which permits unrestricted use, distribution, and reproduction in any medium, provided you give appropriate credit to the original author(s) and the source, provide a link to the Creative Commons license, and indicate if changes were made. The Creative Commons Public Domain Dedication waiver (http://creativecommons.org/publicdomain/zero/1.0/) applies to the data made available in this article, unless otherwise stated. 


\section{Background}

The increasing spread of carbapenemase-producing Enterobacteriaceae (CPE) has been witnessed worldwide over the last decade [1-3]. Therapy of infections caused by these extensively drug-resistant bacteria (XDRB) is limited to few options and associated with an increased morbidity and mortality in comparison with those caused by carbapenem-susceptible strains [4-7]. The large population flows from Southern Africa and Indian sub-continent to the Indian Ocean islands can contribute to the dissemination of XDRB in Reunion Island, a French Overseas Territory located close to Madagascar [8, 9]. Hence, the first two CPE isolates detected in Reunion Island were described in 2011 as NDM-1-producing Klebsiella pneumoniae and Salmonella enterica subsp. enterica (serotype Enteritidis) retrieved from patients previously hospitalized in Mauritius and India, respectively [10]. Likewise, the first OXA-48-like-producing CPE was an OXA-232 produced by Escherichia coli found in 2012 in a Mauritian patient who travelled to India [11]. Spread and epidemiology of CPEs have been previously described in Southern Africa, Arabian peninsula and Indian sub-continent [12-18]. However, these CPEs data in the Southwest Indian Ocean area (consisting of Madagascar, Mayotte and Reunion islands, Mauritius, Comoros and Seychelles archipelagos) are poorly known. Albeit in 2015, $0.04 \%$ of E. coli, $0.19 \%$ of K. pneumoniae, and $0.48 \%$ of Enterobacter cloacae isolates were non-susceptible to imipenem in the diagnostic samples in the health care facilities of Reunion Island [19].

Reunion Island has a population of 850,000 inhabitants and has the same health care level as in mainland France. The University Hospital of Reunion Island (UHRI) is the reference hospital in the Southwest Indian Ocean area (SIOA) for the French overseas people but also for the region inhabitants who need specialized care. The Reunion Island, which connects Europe and the SIOA (with five daily flights), could provide the French mainland territory with NDM-carbapenemase producers [20, 21].

Here we report the results of a CPE surveillance program in Reunion Island. The aim of this study was to investigate the CPE spread in Reunion Island between 2011 and 2016 by characterizing the most prevalent resistance determinants and the clonal spread of these XDRB, especially for Reunionese people who have never travelled abroad.

\section{Methods}

\section{Definitions}

We defined a CPE case as a non-redundant patient infected or colonized with a CPE, i.e. a patient who was not previously known as a CPE carrier in one of the laboratories of the surveillance network. An episode of cross-transmission gathered spatiotemporally linked CPE cases (including those sharing the same healthcare workers) who shared a CPE with the same pulsotype (see below). The grouped-cases by episode were defined as the number of cases for an episode of probable crosstransmission i.e. the index case and all the secondary cases. We selected carbapenemase-producers from EUCAST criteria [22]: non-susceptibility to ertapenem (Minimum Inhibitory Concentration, MIC $>0.5 \mathrm{mg} / \mathrm{L}$ ) and/or to imipenem (MIC $>2 \mathrm{mg} / \mathrm{L}$ ).

\section{Study design}

Since 2008, the regional antimicrobial resistance surveillance system of Reunion Island collects the microbiological tests performed in six laboratories: two private laboratory groups and four laboratories from public hospitals. These four public hospitals include one bi-site University Hospital (with Northern and Southern sites) and two (Western and Eastern) departmental hospitals with a total about 2500 beds and 250,000 hospital admissions per year. This surveillance system is coordinated by the Federation for Nosocomial Infection Control of Reunion Island (French acronym: FELIN Réunion). The representativeness of this network is estimated to be $>90 \%$ of complete-hospitalization days in Reunion Island and 100\% of MSO (Medicine Surgery Obstetrical) hospitalizations. In this surveillance system, patients coming from or with a link with a foreign country or Mayotte were systematically screened for multi drug-resistant (MDR) or XDR bacteria by rectal swab within $24 \mathrm{~h}$ of admission. In addition, intensive care units (ICUs) and burn units of the UHRI systematically screened patients at their entry and weekly thereafter. Strict contact precautions were maintained when a CPE was identified in the screening sample, and contact patients were identified. Hospitalized contact patients were screened by rectal swabbing for CPE carriage and subjected to contact precautions.

We performed a multicentre retrospective review of all consecutive isolates identified and reported as CPE producer by the Federation for Nosocomial Infection Control of Reunion Island surveillance system between January 2011 and December 2016.

\section{Patient clinical data}

Demographics and clinical data were collected from CPE cases: age, gender, date of admission, date of first positive culture, ward, CPE species, anatomical site of isolation, reason for hospitalization, and comorbidities. A patient was considered as exposed to antimicrobial if he had received an antimicrobial treatment within the 3 months before CPE isolation. The link with a foreign country was defined as a residence, stay or hospitalization abroad (including Mayotte Island) in the year before the hospitalization in Reunion Island. Mainland France was not considered as a foreign country. We retrospectively 
followed the CPE patients for a maximum of 30 days after the date of the first positive CPE culture to determine allcause and deaths attributable to CPE infection.

\section{Bacterial isolates and antimicrobial susceptibility testing} Bacterial species were identified using MALDI-TOF mass spectrometry (Microflex, Bruker Daltonics, Breme, Germany) according to the manufacturer's recommendations. We evaluated for each isolate the susceptibility to six relevant antimicrobials, which represent the latest therapeutic alternatives. MICs of ertapenem, imipenem, meropenem, tigecycline and fosfomycin were determined using gradient strips (Etest, bioMérieux, Marcy l'Étoile, France). MICs of colistin were determined by broth microdilution method using UMIC colistin kit (Biocentric, Bandol, France). All MICs were interpreted following the 2019 EUCAST recommendations [22]. Isolates with intrinsic resistance to one of the six antimicrobials were excluded from the calculation of the nonsusceptibility rate of the corresponding antimicrobial.

\section{ESBL and carbapenemase identification}

Genes encoding ESBLs were identified by PCR and sequencing as previously described [23]. We screened all samples with consensus primers targeting $b l a_{\text {СTX }-\mathrm{M}}$, $b l a_{\mathrm{SHV}}$, and $b l a_{\mathrm{TEM}}$ genes. All isolates were evaluated for carbapenemase production by using CARBA-NP test (bioMérieux, La Balme-les-Grottes, France) and GeneXpert system (Cepheid, Sunnyvale, USA) that targets $b l a_{\mathrm{KPC}}, b l a_{\mathrm{NDM}}, b l a_{\mathrm{IMP}}, b l a_{\mathrm{VIM}}$, and $b l a_{\mathrm{OXA}-48 \text {-like }}$ genes $[24,25]$. The presence of carbapenemase-encoding genes $\left(b l a_{\mathrm{KPC}}, \quad b l a_{\mathrm{NDM}}, \quad b l a_{\mathrm{VIM}}, \quad b l a_{\mathrm{IMP}}, \quad b l a_{\mathrm{OXA}-48-1 i k e}\right.$ and $\left.b l a_{\mathrm{IMI}}\right)$ was further confirmed by PCR and sequencing for all isolates by the French Associated National Reference Centre for Antibiotic Resistance (FANRCAR, [26]). The $m c r$ genes were PCR screened by the FANRCAR in colistin-resistant isolates.

\section{Molecular genotyping \\ Pulsed field gel electrophoresis (PFGE) analysis}

E. coli, K. pneumoniae, E. cloacae, Citrobacter freundii, and Serratia marcescens isolates were first genotyped by PFGE using XbaI (Roche Diagnostics, Meylan, France) as previously described [27]. The Bionumerics software (Applied Math, Kortrijk, Belgium) created a DNA similitude matrix based on calculating the Dice profile for pairwise comparison of strains. The dendrogram was built by using the UPGMA (Unweighted Pair Group using Arithmetic Averages) hierarchical algorithm. Pulsotypes were defined according to international recommendations [28]. We applied the threshold of $75 \%$ to define the same pulsotype. A PFGE pattern represented by one isolate was called 'single pulsotype', while a PFGE pattern shared by $\geq 2$ isolates from several patients was called 'major pulsotype'. The pulsotypes of all the isolates of the present collection have been determined in the same laboratory, between May and July 2017.

\section{Multi-locus sequence typing (MLST) analysis}

MLST of E. coli, K. pneumoniae, E. cloacae and C. freundii isolates was performed as described elsewhere [2931]. Hitherto, no MLST scheme exists for S. marcescens. Nucleotide sequences were obtained by Sanger sequencing using Applied Biosystems 3500 Genetic Analyser and Sequencing Analysis software 6. Sequence types (STs) were assigned using the MLST databases of the Warwick Medical School for E. coli (http://mlst.warwick. ac.uk $/ \mathrm{mlst} / \mathrm{dbs} /$ Ecoli) and of the Institut Pasteur for the other species (http://bigsdb.pasteur.fr/). We defined as a cluster, the isolates sharing the same ST.

\section{Statistical analysis}

Poisson regression analysis was used to determine statistical significance of the time trend in CPE incidence. The chosen significance threshold was 0.05 .

\section{Results}

Demographics and clinical characteristics of CPE cases

We identified $53 \mathrm{CPE}$ cases in Reunion Island between 2011 and 2016 and observed a dramatic increase over the study period with only one case in 2011 vs. 21 cases in 2016 (Fig. 1). For instance, in the North site of the University Hospital, one CPE was retrieved out of 4147 rectal screenings in $2011(0.02 \%)$ vs. 21 CPE retrieved out of 5063 rectal screenings in 2016 (0.41\%). Time trend in CPE incidence was explored using Poisson regression analysis and the CPE incidence rate (total number of CPE cases detected each year) increased significantly on average by $62 \%$ per year over the $2011-$ 2016 period (IRR $=1.62 ; p<0.001$ ). Analysis of clinical data showed that $22 \mathrm{CPE}$ cases $(41.5 \%)$ had not travelled abroad and that $31(58.5 \%)$ of CPE cases had travelled abroad. Among them, 16 cases (51.6\%) had an East origin (i.e. a link with Mauritius or Seychelles islands) and 15 cases (48.4\%) a West origin (i.e. a link with Madagascar, Mayotte, or Comoros islands). Mauritius was the most frequent source with $11 \mathrm{CPE}$ cases representing $35.5 \%$ of CPE cases who had travelled abroad (20.8\% of all CPE cases), followed by Mayotte/Comoros (9 cases, 29\%), and Madagascar (6 cases, 19.4\%). Over the last 5 years, the proportion of CPE patients who had travelled abroad accounted for $50 \%$ in 2012 ; $33.3 \%$ in 2013; 60\% in 2014; $56.3 \%$ in 2015 and $66.7 \%$ in 2016 (Fig. 1).

Table 1 summarizes demographics and clinical data of CPE patients. Male patients accounted for $69.8 \%$ of cases and median age was 52 . CPE patients were mainly hospitalized in medical ward (50.9\%) and ICU (35.9\%). 


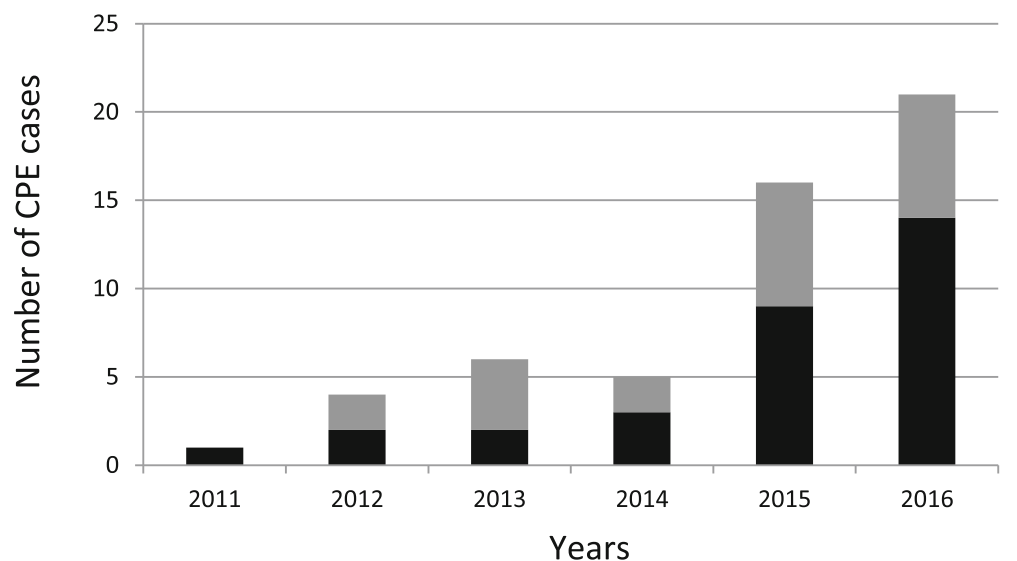

Fig. 1 Number of patients with carbapenemase-producing Enterobacteriaceae (CPE) detected between 2011 and 2016 in Reunion Island (France). The number of CPE cases linked and not with a foreign country is represented by the black and grey bars, respectively. The upward trends in the 'total' $[p<0.001]$, 'linked with a foreign country' $[p<0.001]$ ' and 'not linked with a foreign country' $[p=0.006]$ ' CPE incidence rates (case per patient-days) were significant

Medical evacuation accounted for almost half of all CPE cases (47.2\%). The most frequent sites of isolation were the gut flora $(73.1 \%)$, urine $(13.4 \%)$, and blood (6\%). Treatment data were available for 51 CPE-positive patients. Twelve patients (23.5\%) were treated with carbapenems within the 3 months before the CPE detection. Most of the cases $(84.9 \% ; n=45)$ were colonized with CPE and $15.1 \%(n=8)$ were infected with CPE. Of the 15 deaths in the cohort, four were attributable to CPE (3 bacteraemias and 1 pulmonary infection). Of the $8 \mathrm{CPE}$ infections, 3 (37.5\%) resulted in the death of the infected patients. These 3 deaths were associated with bacteremia. Seven CPE cases (13.2\%) resulted from four episodes of cross-transmission that occurred in two medical wards (ICU and burn units).

\section{Carbapenemase-producing Enterobacteriaceae (CPE)}

We identified 61 CPEs in 53 patients: 47 patients with one CPE, four patients with two CPEs and two patients with three CPEs. One CPE was detected in 2011 (1.6\%), five in 2012 (8.2\%), six in 2013 (9.8\%), six in 2014 (9.8\%), 18 in 2015 (29.5\%), and 25 in 2016 (41\%). The three main species involved were $K$. pneumoniae $(n=26$; $42.6 \%)$, E. coli $(n=13 ; 21.3 \%)$, and E. cloacae $(n=9$; $14.8 \%$ ) (Table 2). Over the 6 years of the study, bla $a_{\mathrm{NDM}}$ was the most frequent and represented $79.4 \%$ of the carbapenemases, followed by bla $_{\mathrm{IMI}}(11.1 \%)$, and $b l a_{\mathrm{IMP}-10}$ (4.8\%). The most common $b l a_{\mathrm{NDM}}$ genes were $b l a_{\mathrm{NDM}-1}$ $(n=42 ; 84 \%)$ and $b l a_{\mathrm{NDM}-5} \quad(n=5 ; 10 \%) . b l a_{\mathrm{NDM}-4}$, $b l a_{\mathrm{NDM}-6}$ and $b l a_{\mathrm{NDM}-7}$ genes were detected in one isolate each. $b l a_{\mathrm{IMI}-1}$ gene accounted for $85.7 \%$ of $b l a_{\mathrm{IMI}}$ group (six out of seven isolates) and always in E. cloacae. One Enterobacter asburiae isolate harboured $b l a_{\mathrm{IMI}-13}$ gene. The three isolates that harboured $b l a_{\mathrm{IMP}-10}$ gene were of $S$. marcescens. Half of the CPE isolates (52.5\%) also harboured an ESBL-encoding gene with $b a_{\mathrm{CTX}-\mathrm{M}-15}$ being the most common. bla $a_{\mathrm{CTX}-\mathrm{M}-15}$ was found in $80.8 \%$ of the $K$. pneumoniae CPE isolates, $46.2 \%$ of $E$. coli CPE isolates and $16.7 \%$ of $C$. freundii CPE isolates. $b l a_{\mathrm{SHV}-12}$ was also detected in two E. coli isolates (data not shown).

\section{Antimicrobial susceptibility testing}

Table 3 reports the antimicrobial susceptibilities of the CPE isolates. Overall, 92, 75, and 71\% of CPE isolates were not susceptible to ertapenem, meropenem, and imipenem, respectively. We reported 33,23 , and $18 \%$ of $\mathrm{CPE}$ isolates non-susceptible to tigecycline, fosfomycin, and colistin, respectively. NDM producers were more frequently non-susceptible to meropenem $(84 \%)$ than to imipenem (66\%). All isolates $(n=7)$ that harboured $b l a_{\text {IMI }}$ gene were resistant to colistin. The three isolates harbouring $b l a_{\mathrm{IMP}-10}$ were all resistant to the six antimicrobials tested.

\section{Molecular genotyping}

PFGE analysis of the $26 \mathrm{~K}$. pneumoniae isolates retrieved one cluster and three major pulsotypes: Cluster A including four ST2193 isolates, pulsotype B including two ST147 isolates, pulsotype C including four ST17 isolates, and pulsotype D including three ST1562 isolates. These 13 isolates harboured both $b l a_{\mathrm{NDM}-1}$ and $b l a_{\mathrm{CTX}-\mathrm{M}-15}$; the isolate KP16 (cluster A) co-expressed bla $a_{\mathrm{NDM}-1}$, $b l a_{\text {OXA-181 }}$, and $b l a_{\text {CTX-M-15 }}$ (Fig. 2). The patients who shared the pulsotypes B and D were hospitalized in the burn unit and those sharing the pulsotype $\mathrm{C}$ were hospitalized in the ICU of the Northern University Hospital. The four patients with the K. pneumoniae ST2193 (cluster A) came from Mauritius. All E. coli isolates displayed different pulsotypes (Fig. 2). Eight STs were identified, 
Table 1 Demographic and clinical data of patients with carbapenemase-producing Enterobacteriaceae (2011-2016, Reunion Island, France). ${ }^{a}$ Patients can report multiple isolate sites for each detected CPE. Six patients harboured the same CPE in two isolate sites

\begin{tabular}{|c|c|}
\hline Demographics & Number (\%) of cases \\
\hline \multicolumn{2}{|l|}{ Gender $(n=53)$} \\
\hline Male & $37(69.8)$ \\
\hline Female & $16(30.2)$ \\
\hline \multicolumn{2}{|l|}{ Age $(n=53)$} \\
\hline $0-18$ & $9(17)$ \\
\hline $19-64$ & $28(52.8)$ \\
\hline$\geq 65$ & $16(30.2)$ \\
\hline median age & 52 \\
\hline \multicolumn{2}{|l|}{ Comorbidities $(n=53)$} \\
\hline high blood pressure & $12(22.6)$ \\
\hline cancer & $10(18.9)$ \\
\hline diabetes mellitus & $8(15.1)$ \\
\hline obesity & $6(11.3)$ \\
\hline ischemic heart disease & $5(9.4)$ \\
\hline chronic obstructive pulmonary disease & $5(9.4)$ \\
\hline liver cirrhosis & $2(3.8)$ \\
\hline \multicolumn{2}{|l|}{ Hospital ward $(n=53)$} \\
\hline medical & $27(50.9)$ \\
\hline ICU & 19 (35.9) \\
\hline surgical & $5(9.4)$ \\
\hline other & $2(3.8)$ \\
\hline medical evacuation & $25(47.2)$ \\
\hline \multicolumn{2}{|l|}{ Isolate site $(n=67)^{\mathrm{a}}$} \\
\hline rectal swab / stool & $49(73.1)$ \\
\hline urine & $9(13.4)$ \\
\hline blood & $4(6)$ \\
\hline sputum & $3(4.5)$ \\
\hline skin / soft tissue & $2(3)$ \\
\hline \multicolumn{2}{|l|}{ Exposure to carbapenems $(n=51)$} \\
\hline imipenem & $9(17.6)$ \\
\hline meropenem & $3(5.9)$ \\
\hline no exposure & $39(76.5)$ \\
\hline \multicolumn{2}{|l|}{ Infections / Colonizations ( $n=53$ ) } \\
\hline infection & $8(15.1)$ \\
\hline colonization & $45(84.9)$ \\
\hline \multicolumn{2}{|l|}{ Cross-transmission $(n=53)$} \\
\hline yes & $7(13.2)$ \\
\hline no & $46(86.8)$ \\
\hline
\end{tabular}

with seven isolates belonging to the clonal complex CC10 (ST167, $n=5$; ST10, $n=2$ ). These isolates harboured $b l a_{\mathrm{NDM}-1}(n=1), b l a_{\mathrm{NDM}-4}(n=1), b l a_{\mathrm{NDM}-5}(n=$
$3)$, and $\operatorname{bla}_{\mathrm{NDM}-6}(n=1)$ and bla $_{\mathrm{OXA}-181}(n=1)$ genes. The nine carbapenemase-producing $E$. cloacae isolates clustered in two major pulsotypes. The pulsotype E (two ST106 isolates with $\left.b l a_{\mathrm{NDM}-1}\right)$ was shared by two patients from the burn unit of Northern University Hospital, while the pulsotype F (six ST820 isolates harbouring $\left.b l a_{\mathrm{IMI}-1}\right)$ came from patients previously hospitalized in Mayotte Island. The six bla $a_{\mathrm{NDM}-1} C$. freundii isolates had unique pulsotypes. In contrast, the three $S$. marcescens isolates belonged to the same pulsotype G, harboured $b l a_{\mathrm{IMP}-10}$, and came from three patients previously hospitalized in the same private clinic in Mauritius.

We found six episodes of cross-transmission. Two of them (E. cloacae ST820 - pulsotype F, and S. marcescens pulsotype G) gathered patients from the same origin (Mayotte/Comoros and Mauritius, respectively). The other four episodes of cross-transmission of CPE occurred in the Northern University Hospital. The $K$. pneumoniae ST147 (bla $a_{\mathrm{NDM}-1}$; pulsotype B) was shared by two patients with no history of travel abroad. $K$. pneumoniae ST17 (bla $a_{\mathrm{NDM}-1}$; pulsotype $\mathrm{C}$ ) has been possibly transmitted in ICU from a patient who had travelled in Madagascar (KP1) to three patients who had stayed in Reunion Island (KP2, KP6, KP8). Likewise, $K$. pneumoniae ST1562 (bla $a_{\mathrm{NDM}-1}$; pulsotype D) have been possibly transmitted in the burn unit from a Madagascar-linked patient (KP4) to two patients who had stayed in Reunion Island (KP5, KP26). However, the low percentage of similarity of these three isolates $(\sim$ 75\%) made it difficult to draw firm conclusions and could suggest an indirect transmission. Similarly, E. cloacae ST106 (bla NDM-1 $_{1}$; pulsotype E) has been transmitted in the burn unit from a Mayotte-related patient (Eclo2) to one patient with no history of travel abroad. Overall, we found that 16 out of the 53 CPE cases in Reunion Island were not - directly or indirectly - linked to a foreign country. Since we could have missed less obvious links between CPE carriers and foreign countries, we can consider that a maximum of $30.2 \%$ of CPE cases in the Reunion island were autochtonous. In contrast, 37 patients $(69.8 \%)$ were linked to a foreign country, directly $(n=31$; with a history of travel abroad) or indirectly ( $n=6$; through the contact with a CPE patient who had travelled abroad).

\section{Discussion}

The global emergence of CPEs is a growing concern and data from the Southern Indian Ocean area are scarce. Here we report the first epidemiological and genotyping analysis of CPEs in an island of this area over a six-year period.

Our study reports an increasing number of CPE cases from 2011 to 2016, in line with the results of surveillance conducted by Santé Publique France institute in 
Table 2 Distribution of 61 CPE isolates harbouring 63 carbapenemase-encoding genes (2011-2016, Reunion Island, France). ${ }^{a}$ Two isolates harboured two carbapenemase-encoding genes: one K. pneumoniae isolate harboured bla $a_{\mathrm{NDM}-1}$ and b/a $a_{\mathrm{OXA}-181}$, and one $E$. coli isolate harboured bla $a_{\mathrm{NDM}-1}$ and bla $a_{\mathrm{VIM}-2}$

\begin{tabular}{|c|c|c|c|c|c|c|c|c|c|c|c|}
\hline \multirow[t]{3}{*}{ Species } & \multicolumn{11}{|c|}{ Type of carbapenemase-encoding genes ${ }^{a}$} \\
\hline & \multicolumn{5}{|l|}{$b / a_{\mathrm{NDM}}$} & \multirow{2}{*}{$\begin{array}{l}b l a_{\mathrm{OXA}} \\
b l a_{\mathrm{OXA}-181}\end{array}$} & \multicolumn{2}{|l|}{$b / a_{\mid \mathrm{MI}}$} & \multirow{2}{*}{$\begin{array}{l}b / a_{\mathrm{IMP}} \\
b / a_{\mathrm{IMP}-10}\end{array}$} & \multirow{2}{*}{$\begin{array}{l}\text { bla }_{\mathrm{VIM}} \\
\text { bla }_{\mathrm{VIM}-2}\end{array}$} & \multirow[t]{2}{*}{ Total } \\
\hline & $b / a_{N D M-1}$ & $b^{\prime} a_{N D M-4}$ & $b^{\prime} a_{N D M-5}$ & $b l a_{N D M-6}$ & $b / a_{N D M-7}$ & & $b / a_{\mid \mathrm{MI}-1}$ & $b / a_{\mid \mathrm{MI}-13}$ & & & \\
\hline K. pneumoniae & 24 & & 1 & & 1 & $1^{a}$ & & & & & 27 \\
\hline E. coli & 6 & 1 & 4 & 1 & & 1 & & & & $1^{\mathrm{a}}$ & 14 \\
\hline E. cloacae & 3 & & & & & & 6 & & & & 9 \\
\hline C. freundii & 6 & & & & & & & & & & 6 \\
\hline S. marcescens & & & & & & & & & 3 & & 3 \\
\hline E. asburiae & & & & & & & & 1 & & & 1 \\
\hline E. kobei & 1 & & & & & & & & & & 1 \\
\hline P. mirabilis & 1 & & & & & & & & & & 1 \\
\hline S. enterica subsp. enterica & 1 & & & & & & & & & & 1 \\
\hline Total & 42 & 1 & 5 & 1 & 1 & 2 & 6 & 1 & 3 & 1 & 63 \\
\hline
\end{tabular}

France [32]. Among the French regions, Reunion Island has the fourth highest CPE incidence with 3.8 episodes per 100,000 inhabitants over the period 2004-2015 [32]. The origin of CPE carriers differs between Reunion Island and mainland France. Hence, the proportion of CPE cases in mainland France who had travelled abroad was $47 \%$ over the period 2004-2015 and decreased overtime. This proportion is higher in the Reunion Island, with 58.5\% (31/53) of the CPE cases between 2011 and 2016 who had travelled abroad. This difference most probably results from the growing population flows between the Indian Ocean islands, and the increasing number of medical evacuations towards Reunion Island (125 in 2011 vs. 300 in 2016). Patients repatriated from Mauritius likely had the highest rate of CPE carriage.
While this country provides $5 \%$ of the medical evacuations, 35.5\% (11/31) of CPE cases in Reunion Island with an external origin came from Mauritius $(20.8 \%$ of all CPE cases).

CPE patients with no history of travel abroad represented $41.5 \%(n=22)$ of the CPE cases. Genotyping analysis suggested three episodes of cross-transmissions in the UHRI of isolates recovered from patients who had travelled abroad. Overall, only $30.2 \%$ of all CPE cases $(n=16)$ had no direct or indirect (i.e. via a crosstransmission) link with a foreign country. This proportion of cases unrelated abroad is low compared to French national data over the same period (53\%). This result is probably linked to the more recent introduction of CPEs on Reunion Island (2011 vs. 2004 in mainland

Table 3 Antimicrobial susceptibilities of the 61 CPE isolates (2011-2016, Reunion Island, France). ${ }^{a}$ Two isolates harboured two carbapenemase-encoding genes: one K. pneumoniae isolate harboured bla $a_{\mathrm{NDM}-1}$ and $b / a_{\mathrm{OXA}-181}$, and one E. coli isolate harboured bla $a_{\mathrm{NDM}-1}$ and b/a $a_{\mathrm{VIM}-2}{ }^{b}{ }^{b}$ The clinical breakpoints for imipenem $(0.125-4)$ were used to determine the susceptibility of the isolate of $P$. mirabilis. ' Because of the intrinsic resistance of the $P$. mirabilis species to tigecycline, one isolate of $P$. mirabilis harbouring bla ${ }_{\mathrm{NDM}}-1$ was excluded for the calculation of non-susceptibility rate of tigecycline. The PK/PD clinical breakpoints for tigecycline (EUCAST 2019; 0.5-0.5) were used to determine the susceptibility of other isolates than E. coli. ${ }^{d}$ Because of the intrinsic resistance of the S. marcescens and $P$. mirabilis species to colistin, one isolate of P.mirabilis harbouring bla $a_{N D M-1}$ and 3 isolates of S.marcescens harbored bla $a_{1 \mathrm{MP}-10}$ were excluded for the calculation of non-susceptibility rate of colistin (N.D.: not determined)

\begin{tabular}{|c|c|c|c|c|c|c|c|c|c|}
\hline \multirow[t]{3}{*}{ Antimicrobials } & \multicolumn{5}{|c|}{$\begin{array}{l}\text { Carbapenemase-encoding genes } \\
\text { (\% of non-susceptible isolates) }\end{array}$} & \multicolumn{2}{|c|}{$\begin{array}{l}\text { MIC Range } \\
(\mathrm{mg} / \mathrm{L})\end{array}$} & \multirow[t]{3}{*}{$\begin{array}{l}\mathrm{MIC}_{50} \\
(\mathrm{mg} / \mathrm{L})\end{array}$} & \multirow[t]{3}{*}{$\begin{array}{l}\mathrm{MIC}_{90} \\
(\mathrm{mg} / \mathrm{L}\end{array}$} \\
\hline & bla $_{\mathrm{NDM}}{ }^{a}$ & $b l a_{\mid \mathrm{MI}}$ & bla $a_{\mathrm{MP}-10}$ & bla OXA-181 & Total & Min. & Max. & & \\
\hline & $(n=50)$ & $(n=7)$ & $(n=3)$ & $(n=1)$ & $(n=61)$ & & & & \\
\hline Ertapenem & 96 & 71.4 & 100 & 0 & 91.8 & 0.25 & 32 & 8 & 32 \\
\hline Imipenem & $66^{\mathrm{b}}$ & 100 & 100 & 0 & $70.5^{b}$ & 0.5 & 32 & 6 & 32 \\
\hline Meropenem & 84 & 14.3 & 100 & 0 & 75.4 & 1 & 32 & 6 & 32 \\
\hline Tigecycline & $34.7^{c}$ & 14.3 & 100 & 0 & $33.3^{c}$ & 0.032 & 24 & 0.38 & 6 \\
\hline Colistin & $6.1^{d}$ & 100 & $N D^{d}$ & 0 & $17.5^{d}$ & 0.06 & 64 & 0.25 & 32 \\
\hline Fosfomycin & 22 & 0 & 100 & 0 & 23 & 0.125 & 1024 & 12 & 128 \\
\hline
\end{tabular}




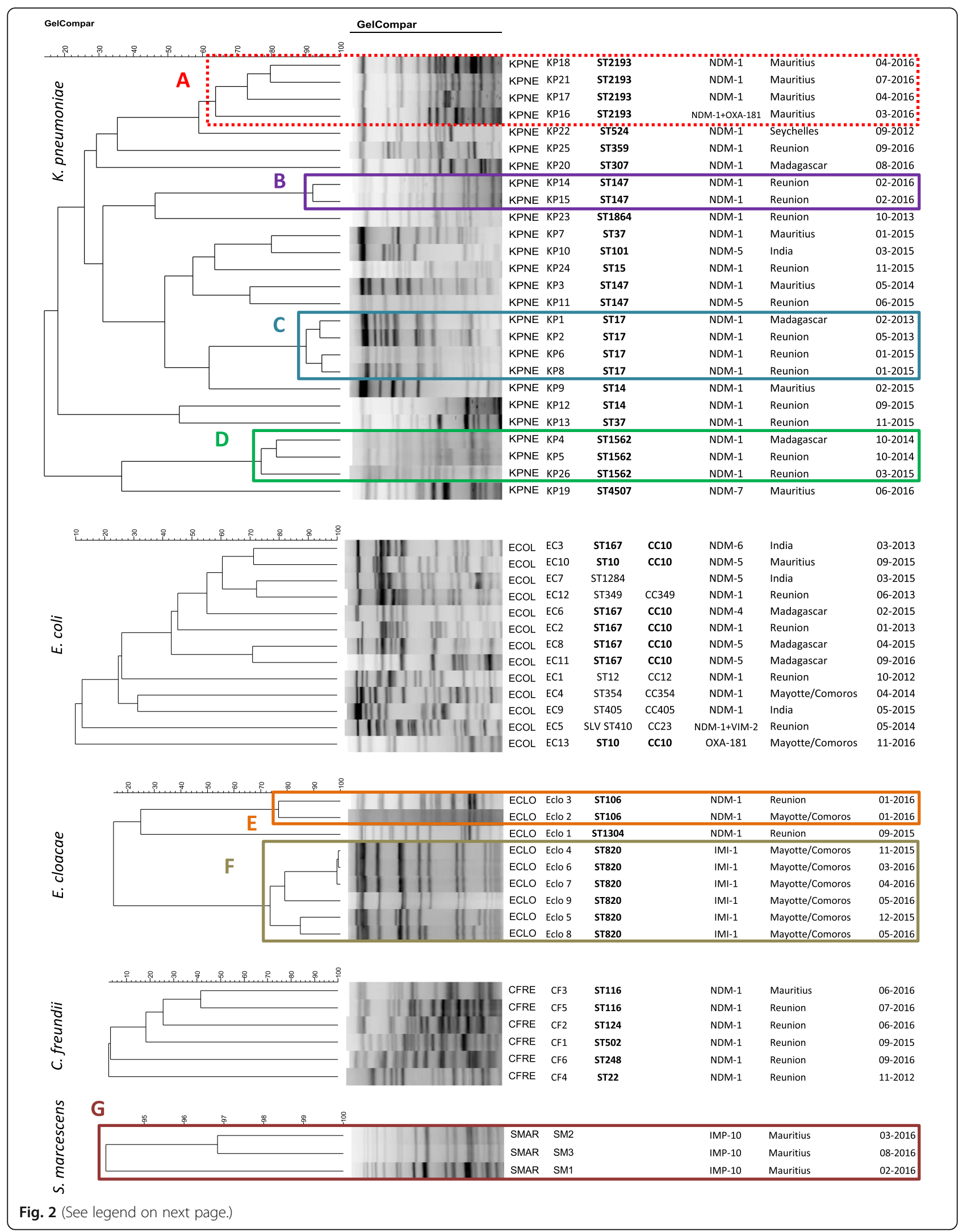


(See figure on previous page.)

Fig. 2 Molecular genotyping (PFGE and MLST analysis) applied to 57 CPE isolates of K. pneumoniae, E. coli, E. cloacae, C. freundii, and S. marcescens (2011-2016, Reunion Island, France). There is not MLST scheme definition for S. marcescens. Data presented: PFGE pattern, bacterial species (KPNE, K. pneumoniae; ECOL, E. coli; ECLO, E. cloacae; CFRE, C. freundii, SMAR, S. marcescens), sequence type, clonal complex, carbapenemase(s) produced, foreign country visited by the patient within the year before CPE isolation, month and year of CPE isolation. The similarity scales are specific of each bacterial species. The optimization and band-tolerance values used for PFGE dendrogram were 1\%

France) and also highlights the strong import pressure to which this French Overseas Territory is subjected.

The most prevalent resistance mechanism was $b l a_{\mathrm{NDM}}$ (79.4\%). This epidemiology is radically different from that in mainland France (dominated by $b l a_{\mathrm{OXA}-48-\text { like }}$ ) and reflects the connection between Reunion Island and Indian sub-continent mainly via Mauritius and Seychelles islands. Spread of bla $a_{\mathrm{NDM}}$ in Southern Africa is more complex. NDM-1 carbapenemase was successively described in Kenya and South Africa in 2011, in Tanzania in 2014, and in Madagascar in 2015 [12, 13, 33, 34]. However, tracking $b l a_{\mathrm{NDM}}$ dissemination is difficult because Indian population travel in all these countries directly or via the Indian Ocean islands. Reunion Island has already provided France with NDM producers over the last decade [32] but can become the predominant gateway with the spread of NDM producers in the SIOA. For example, Reunion Island was the second largest supplier of NDM producers in France in the period 2004-2015 (28 isolates for just 850, 000 inhabitants), tied with the Provence-Alpes-Côte d'Azur region (28 isolates, 5.1 million inhabitants) and behind the Ile de France region (164 isolates, 12.2 million inhabitants) [32]. The second resistance mechanism was bla $_{\mathrm{IMI}}(11.1 \%)$. The proportion of IMI carbapenemase is ten times higher in Reunion than in mainland France [35]. This high prevalence is due to an on-going outbreak of IMI-1 E. cloacae in Mayotte Island [36]. The third most prevalent resistance mechanism was bla $_{\mathrm{IMP}-10}(4.8 \%)$, harboured by a $S$. marcescens isolates. This proportion is also higher than that reported in mainland France $(0.2 \%)$ and is presumably due to a nosocomial transmission in a Mauritian clinic [35].

The global rate of resistance to colistin (17.5\%) was higher than that reported in the 2016 French National survey (6.8\% in CPE) [35]. This high rate was probably due to the chromosomally encoded hetero-resistance to colistin and depending on the PhoP/PhoQ two component regulatory system of the IMI-1 E. cloacae strains (cluster XI) which accounted for $9.8 \%$ of the isolates [37]. The rate of resistance to colistin in NDM producers (that included isolates of intrinsically resistant Proteus sp. or Serratia sp.) was similar to national data (8.0\% vs. $8.4 \%)$. No isolate harboured $\mathrm{mor}$ plasmidmediated resistance genes. The emergence of IMP-10 S. marcescens is of concern because the three isolates recovered were non-susceptible to all antimicrobials commonly used to treat CPE infections (Table 3).
Genotypic data (PFGE and MLST) identified 25 CPEs isolated from patients with no history of travel abroad. PFGE analysis suggested that six of them (24\%) acquired a CPE isolate from a patient who had travelled abroad (Fig. 2). However, the low percentage of similarity of some isolates ( $\sim 75 \%$ for pulsotype D or F) does not allow to assert this transmission with certainty and constitutes a limitation of our study. The high diversity of the genetic background of the CPE isolated from patients with no direct or indirect link with a foreign country suggests multiple transfers of $b l a_{\mathrm{NDM}}$ among local isolates of Reunion Island. On the other hand, K. pneumoniae ST147 and E. coli ST167 have already been shown to harbour $b l a_{\mathrm{NDM}}$ and could participate in clonal dissemination of this carbapenemase family $[38,39]$.

\section{Conclusions}

About two-thirds of the patients and the isolates collected in Reunion Island were linked with a foreign country. Therefore, we can reasonably think that the present collection mirrors the epidemiology of CPE of the Indian Ocean area. Besides, most CPE isolates with no link with a foreign country are not clonally related, demonstrating the local spread of carbapenemaseencoding genes (i.e. $b l a_{\mathrm{NDM}}$ ) in a polyclonal bacterial population.

\section{Abbreviations}

CC: Clonal Complex; CPE: Carbapenemase Producing Enterobacteriaceae; CTXM: Cefotaximase-Munich; ESBL: Extended Spectrum Beta Lactamase; EUCAST: European Committee on Antimicrobial Susceptibility Testing; FANRCAR: French Associated National Reference Centre for Antibiotic Resistance; FELIN: Fédération de Lutte contre les Infections Nosocomiales; ICU: Intensive Care Unit; IMI: Imipenemase; IMP: Imipenemase; IRR: Incidence Rate Ratio; MALDI-TOF: Matrix Assisted Laser Desorption lonisation-Time Of Flight; MDR: Multi Drug Resistant; MIC: Minimum Inhibitory Concentration; MLST: Multi Locus Sequence Typing; MSO: Medicine Surgery Obstetrical; ND: Not Determined; NDM: New Dehli Metallobetalactamase;

OXA: Oxacillinase; PCR: Polymerase Chain Reaction; PFGE: Pulsed Field Gel Electrophoresis; SHV: Sulfo Hydryl Variable; SIOA: Southwest Indian Ocean area; ST: Sequence Type; TEM: Temoneira; UHRI: University Hospital of Reunion Island; UPGMA: Unweighted Pair Group using Arithmetic Averages; XDRB: eXtensively Drug Resistant Bacteria

\section{Acknowledgments}

The authors thank the French Associated National Reference Centre for Antibiotic Resistance for carbapenemase PCR confirmation and sequencing. The authors thank Houssein Gbaguidi Haore for statistical analysis.

\section{Authors' contributions}

GM designed the study, contributed to acquisition, analysis and interpretation of data; drafted the manuscript and has given final approval of this version; PC, DM, MT, PS, AL contributed to analysis and interpretation of data, drafted the manuscript and have given final approval of this version; 
NT, BR, MCJB, NL, CBC, MR, SP, AL, GM, JA, NA contributed to acquisition of data and have given final approval of this version; $\mathrm{PM}, \mathrm{OB}, \mathrm{XB}$, contributed to analysis and interpretation of data, revised the manuscript critically for important intellectual content and have given final approval of this version; $\mathrm{DH}$ designed the study, contributed to acquisition, analysis and interpretation of data; drafted the manuscript and has given final approval of this version. All authors read and approved the final manuscript.

\section{Funding}

This study was partly supported by the Indian Ocean Regional Health Agency (ARS-OI)

\section{Availability of data and materials}

The datasets analysed during the current study are available from the corresponding author on reasonable request.

\section{Ethics approval and consent to participate}

The study was approved by the ethical committee 'Comité de Protection des Personnes - Ouest III' under the number 2017-A02640-53.

\section{Consent for publication}

All parties consented to publications of results.

\section{Competing interests}

None declared.

\section{Author details}

'Laboratoire de Bactériologie, CHU Félix Guyon, Allée des Topazes, 97400 Saint-Denis, La Réunion, France. ²UMR Processus Infectieux en Milieu Insulaire Tropical, CNRS 9192, INSERM U1187, IRD 249, Université de La Réunion, Sainte-Clotilde, La Réunion, France. ${ }^{3}$ Laboratoire d'Hygiène Hospitalière, CHRU Jean Minjoz, Besançon, France. ${ }^{4}$ UMR Chrono-Environnement, CNRS 6249, Université de Bourgogne Franche-Comté, Besançon, France. ${ }^{5}$ Service d'hygiène hospitalière, CHU Félix Guyon, Saint-Denis, La Réunion, France. ${ }^{6}$ Laboratoires Réunilab, Sainte-Clotilde, La Réunion, France. ${ }^{7}$ Laboratoires Cerballiance, Le Port, La Réunion, France. ${ }^{8}$ Laboratoire de Bactériologie, Groupe Hospitalier Sud Réunion, Saint-Pierre, La Réunion, France. ${ }^{9}$ Laboratoire de biologie, Centre Hospitalier Gabriel Martin, Saint-Paul, La Réunion, France. ${ }^{10}$ Laboratoire de biologie, Groupe Hospitalier Est Réunion, Saint-Benoit, La Réunion, France. ${ }^{11}$ Service de Réanimation polyvalente. Département d'Informatique clinique, CHU Félix Guyon, Saint-Denis, La Réunion, France.

\section{Received: 16 August 2019 Accepted: 14 February 2020}

\section{Published online: 19 February 2020}

\section{References}

1. Albiger B, Glasner C, Struelens MJ, Grundmann H, Monnet DL. the European Survey of Carbapenemase-Producing Enterobacteriaceae (EuSCAPE) working group. Carbapenemase-producing Enterobacteriaceae in Europe: assessment by national experts from 38 countries, May 2015. Euro Surveill. 2015;20(45).

2. Nordmann P, Naas T, Poirel L. Global spread of Carbapenemase-producing Enterobacteriaceae. Emerg Infect Dis. 2011;17(10):1791-8.

3. Cantón R, Akóva M, Carmeli Y, Giske CG, Glupczynski Y, Gniadkowski M, et al. Rapid evolution and spread of carbapenemases among Enterobacteriaceae in Europe. Clin Microbiol Infect. 2012;18(5):413-31.

4. Hirsch EB, Tam VH. Detection and treatment options for Klebsiella pneumoniae carbapenemases (KPCs): an emerging cause of multidrugresistant infection. J Antimicrob Chemother. 2010;65(6):1119-25.

5. Falagas ME, Karageorgopoulos DE, Nordmann P. Therapeutic options for infections with Enterobacteriaceae producing carbapenem-hydrolyzing enzymes. Future Microbiol. 2011;6(6):653-66.

6. Akova M, Daikos GL, Tzouvelekis L, Carmeli Y. Interventional strategies and current clinical experience with carbapenemase-producing gram-negative bacteria. Clin Microbiol Infect. 2012;18(5):439-48.

7. Borer A, Saidel-Odes L, Riesenberg K, Eskira S, Peled N, Nativ R, et al. Attributable mortality rate for carbapenem-resistant Klebsiella pneumoniae bacteremia. Infect Control Hosp Epidemiol. 2009;30(10):972-6.

8. Poirel L, Lascols C, Bernabeu S, Nordmann P. NDM-1-producing Klebsiella pneumoniae in Mauritius. Antimicrob Agents Chemother. 2012;56(1):598-9.
9. Holman AM, Allyn J, Miltgen G, Lugagne N, Traversier N, Picot S, et al. Surveillance of carbapenemase-producing Enterobacteriaceae in the Indian Ocean region between January 2010 and December 2015. Med Mal Infect. 2017;47(5):333-9.

10. Cabanes F, Lemant J, Picot S, Simac C, Cousty J, Jalin L, et al. Emergence of Klebsiella pneumoniae and Salmonella Metallo-Beta-lactamase (NDM-1) producers on Reunion Island. J Clin Microbiol. 2012;50(11):3812.

11. Potron A, Rondinaud E, Poirel L, Belmonte O, Boyer S, Camiade S, et al. Genetic and biochemical characterisation of OXA-232, a carbapenemhydrolysing class D $\beta$-lactamase from Enterobacteriaceae. Int J Antimicrob Agents. 2013;41(4):325-9.

12. Poirel $L$, Revathi G, Bernabeu $S$, Nordmann P. Detection of NDM-1producing Klebsiella pneumoniae in Kenya. Antimicrob Agents Chemother. 2011:55(2):934-6.

13. Mushi MF, Mshana SE, Imirzalioglu C, Bwanga F. Carbapenemase genes among multidrug resistant gram negative clinical isolates from a tertiary hospital in Mwanza. Tanzania Biomed Res Int. 2014;2014:303104.

14. Perovic O, Britz E, Chetty V, Singh-Moodley A. Molecular detection of carbapenemase-producing genes in referral Enterobacteriaceae in South Africa: a short report. South Afr Med J. 2016;106(10):975-7.

15. Zowawi HM, Balkhy HH, Walsh TR, Paterson DL. $\beta$-Lactamase production in key gram-negative pathogen isolates from the Arabian peninsula. Clin Microbiol Rev. 2013;26(3):361-80.

16. Zowawi HM, Sartor AL, Balkhy HH, Walsh TR, Al Johani SM, AlJindan RY, et al. Molecular characterization of carbapenemase-producing Escherichia coli and Klebsiella pneumoniae in the countries of the Gulf cooperation council: dominance of OXA-48 and NDM producers. Antimicrob Agents Chemother. 2014;58(6):3085-90.

17. Hall JM, Corea E, Sanjeewani HDA, Inglis TJJ. Molecular mechanisms of $\beta$ lactam resistance in carbapenemase-producing Klebsiella pneumoniae from Sri Lanka. J Med Microbiol. 2014;63(Pt 8):1087-92.

18. Castanheira M, Deshpande LM, Mathai D, Bell JM, Jones RN, Mendes RE. Early dissemination of NDM-1- and OXA-181-producing Enterobacteriaceae in Indian hospitals: report from the SENTRY antimicrobial surveillance program, 2006-2007. Antimicrob Agents Chemother. 2011;55(3):1274-8.

19. Avril C, Simac C. Réseau de surveillance régional des résistances aux antibiotiques, La Réunion. Bilan annuel 2015. ARLIN-FELIN Réunion-Mayotte. http://www.felin.re/spip.php?rubrique67

20. Dortet L, Cuzon G, Ponties V, Nordmann P. Trends in carbapenemaseproducing Enterobacteriaceae, France, 2012 to 2014. Euro Surveill. 2017;22(6).

21. Gauthier L, Dortet L, Cotellon G, Creton E, Cuzon G, Ponties V, et al. Diversity of Carbapenemase-producing Escherichia coli isolates in France in 2012-2013. Antimicrob Agents Chemother. 2018;27, 62(8).

22. European Committee on Antimicrobial Susceptibility Testing - Comité de l'Antibiogramme de la Société Française de Microbiologie. Recommandations 2019. Version 2, Mai 2019. http:// www.sfmmicrobiologie.org/wp-content/uploads/2019/05/CASFM2019_V2.0_MAI.pdf

23. Bréchet $C$, Plantin J, Sauget $M$, Thouverez $M$, Talon D, Cholley $P$, et al. Wastewater treatment plants release large amounts of extended-spectrum $\beta$-lactamase-producing Escherichia coli into the environment. Clin Infect Dis. 2014;58(12):1658-65

24. Dortet L, Poirel L, Nordmann P. Rapid identification of carbapenemase types in Enterobacteriaceae and Pseudomonas spp. by using a biochemical test. Antimicrob Agents Chemother. 2012;56(12):6437-40.

25. McMullen AR, Yarbrough ML, Wallace MA, Shupe A, Burnham C-AD. Evaluation of genotypic and phenotypic methods to detect Carbapenemase production in gram-negative bacilli. Clin Chem. 2017;63(3):723-30.

26. Nordmann P, Poirel L. Strategies for identification of carbapenemaseproducing Enterobacteriaceae. J Antimicrob Chemother. 2013;68(3):487-9.

27. Cholley P, Thouverez M, Gbaguidi-Haore H, Sauget M, Slekovec C, Bertrand X, et al. Hospital cross-transmission of extended-spectrum $\beta$-lactamase producing Escherichia coli and Klebsiella pneumoniae. Med Mal Infect. 2013;43(8):331-6.

28. Tenover FC, Arbeit RD, Goering RV, Mickelsen PA, Murray BE, Persing DH, et al. Interpreting chromosomal DNA restriction patterns produced by pulsed-field gel electrophoresis: criteria for bacterial strain typing. J Clin Microbiol. 1995;33(9):2233-9.

29. Wirth T, Falush D, Lan R, Colles F, Mensa P, Wieler LH, et al. Sex and virulence in Escherichia coli: an evolutionary perspective. Mol Microbiol. 2006:60(5):1136-51.

30. Diancourt L, Passet V, Verhoef J, Grimont PAD, Brisse S. Multilocus sequence typing of Klebsiella pneumoniae nosocomial isolates. J Clin Microbiol. 2005; 43(8):4178-82 
31. Miyoshi-Akiyama T, Hayakawa K, Ohmagari N, Shimojima M, Kirikae T. Multilocus Sequence Typing (MLST) for Characterization of Enterobacter cloacae. PLoS One. 2013;8(6).

32. Épisodes impliquant des entérobactéries productrices de carbapénèmases (EPC) en France, de 2004 à 2015. Bilan épidémiologique national au 31 Décembre 2015. Santé Publique France. http://invs.santepubliquefrance.fr/ Dossiers-thematiques/Maladies-infectieuses/Infections-associees-aux-soins/ Surveillance-des-infections-associees-aux-soins-IAS/Enterobacteriesproductrices-de-carbapenemases-EPC/Episodes-impliquant-des-EPC-enFrance-Situation-epidemiologique-du-31-decembre-2015.

33. Lowman W, Sriruttan C, Nana T, Bosman N, Duse A, Venturas J, et al. NDM-1 has arrived: first report of a carbapenem resistance mechanism in South Africa. S Afr Med J. 2011;101(12):873-5.

34. Chereau F, Herindrainy P, Garin B, Huynh B-T, Randrianirina F, Padget M, et al. Colonization of extended-spectrum- $\beta$-lactamase- and NDM-1producing Enterobacteriaceae among pregnant women in the community in a low-income country: a potential reservoir for transmission of multiresistant Enterobacteriaceae to neonates. Antimicrob Agents Chemother. 2015;59(6):3652-5.

35. Plésiat P, Cattoir V, Bonnet R, Dortet L. Centre National de Référence de la Résistance aux Antibiotiques. Rapport d'activités. 2016; http://www.cnrresistance-antibiotiques.fr/ressources/pages/Rapport_CNR_2016.pdf.

36. Miltgen $G$, Bonnin RA, Avril C, Benoit-Cattin T, Martak D, Leclaire A, et al. Outbreak of IMI-1 Carbapenemase-producing colistin-resistant Enterobacter cloacae on the French island of Mayotte (Indian Ocean). Int J Antimicrob Agents. 2018;52(3):416-20.

37. Guérin F, Isnard C, Sinel C, Morand P, Dhalluin A, Cattoir V, et al. Clusterdependent colistin hetero-resistance in Enterobacter cloacae complex. J Antimicrob Chemother. 2016 Nov;71(11):3058-61.

38. Giske CG, Fröding I, Hasan CM, Turlej-Rogacka A, Toleman M, Livermore D, et al. Diverse sequence types of Klebsiella pneumoniae contribute to the dissemination of blaNDM-1 in India, Sweden, and the United Kingdom. Antimicrob Agents Chemother. 2012;56(5):2735-8.

39. Zhang R, Liu L, Zhou H, Chan EW, Li J, Fang Y, et al. Nationwide surveillance of clinical Carbapenem-resistant Enterobacteriaceae (CRE) strains in China. EBioMedicine. 2017;19:98-106.

\section{Publisher's Note}

Springer Nature remains neutral with regard to jurisdictional claims in published maps and institutional affiliations.

Ready to submit your research? Choose BMC and benefit from:

- fast, convenient online submission

- thorough peer review by experienced researchers in your field

- rapid publication on acceptance

- support for research data, including large and complex data types

- gold Open Access which fosters wider collaboration and increased citations

- maximum visibility for your research: over $100 \mathrm{M}$ website views per year

At $\mathrm{BMC}$, research is always in progress.

Learn more biomedcentral.com/submissions 